\title{
TECHNICAL CHANGE AND FIRM SIZE: THE PHARMACEUTICAL INDUSTRY
}

\author{
John M. Vernon and Peter Gusen
}

\section{Introduction}

$\mathbf{F}$ ISHER and TEMIN (1973) have argued recently that many empirical studies ${ }^{1}$ relating to the Schumpeterian hypothesis are inappropriate for testing that hypothesis. They observe that Schumpeter can be interpreted as hypothesizing that the elasticity of the value of research and development ( $R$ and $D$ ) output with respect to firm size is greater than unity. On the other hand, the empirical studies have been concerned with investigating the elasticity of $R$ and $D$ inputs with respect to firm size.

Fisher and Temin demonstrate that a finding that the $\mathrm{R}$ and $\mathrm{D}$ input elasticity exceeds unity does not imply that the $R$ and $D$ output elasticity exceeds unity also. Given that public policy formulation should be based on tests of the Schumpeter hypothesis rather than on tests of the $R$ and $D$ input elasticity, their point is well taken. Of course, in defense of the empirical studies, it can be argued that data limitations have restricted testing to the $R$ and $D$ input elasticity, and that most of the researchers have been aware that they were not testing the Schumpeter hypothesis.

In a footnote, Fisher and Temin refer to a study of technical change in the pharmaceutical industry that does attempt to test the Schumpeter hypothesis directly. ${ }^{2}$ This study by Comanor (1965) examines the relationships among firm size, $\mathrm{R}$ and $\mathrm{D}$ inputs, and technical change in the United States pharmaceutical in-

Received for publication July 5, 1973. Revision accepted for publication January 16, 1974.

The authors are grateful to M. A. Adelman, M. Bronfenbrenner, D. Davies, F. Fisher, W. Gruber, T. Seaks and D. Schwartzman, and an anonymous referee for helpful comments. We are especially indebted to $\mathrm{H}$. Grabowski for his very thorough criticisms of the first draft. All errors and judgments are the authors' responsibility.

1 Fisher and Temin refer to the studies by Villard (1958), Schmookler (1959), Worley (1961), Mansfield (1964), Scherer (1965), and Comanor (1967).

2 In addition to the 1965 Comanor study, Mansfield (1964) and Scherer (1965) also have made studies that fall into this category. For a summary of both studies, see Vernon (1972). dustry for the period 1955-1960. The amount of technical change accomplished by a firm is measured by its sales during the first two years following introduction of all new chemical entities. An important conclusion of the study was that "... there are substantial diseconomies of scale in $\mathrm{R}$ and $\mathrm{D}$ which are associated with large firm size." (Comanor, 1965, p. 190).

Because the pharmaceutical industry is one of the rare industries for which adequate data are available to test the Schumpeter hypothesis directly, we have attempted to test the hypothesis in that industry for the more recent period, 1965-1970. Another reason for our work was to try to overcome some difficulties in Comanor's analysis that raise ambiguities of interpretation. As we shall report, our work leads to results that are essentially opposite those of Comanor.

Our finding for the 1965-1970 period, that larger firms were "better" at innovation than smaller firms, has another interesting implication. That is, accepting Comanor's findings of the opposite case for the 1955-1960 period, one might be led to hypothesize that the 1962 Amendments to the Food, Drug and Cosmetic Act inadvertently provided an advantage to larger firms. The 1962 Amendments added a "proof-of-efficacy" requirement to the "proofof-safety" requirement of the 1938 Food, Drug and Cosmetic Act. In effect, the 1962 Amendments increased the costs associated with introducing new drugs by requiring extensive tests and evaluations not required previously.

In order to investigate further the effect of the 1962 Amendments, we applied our model to 1955-1960 data. We found that larger firms were "better" at developing new chemical entities in that period also, but their relative advantage over smaller firms was smaller than in the post-1962 period (see footnote 18).

The plan of this paper is as follows: First, we summarize and point out several problems we found with Comanor's study. Section III presents the results from a two-equation model that decomposes the technical change measure 
into an $\mathrm{R}$ and $\mathrm{D}$ component and a marketing component.

The final section is an analysis of the elasticity of technical change with respect to firm size. The total elasticity is shown to consist of two parts - a "direct" and an "indirect" effect of size. The indirect effect is the effect on technical change of the increase in $R$ and $D$ inputs (induced by an increase in firm size). In this section we make use also of a maximum likelihood estimation technique developed by Tobin (1958) for cases where the dependent variable is limited, as is the case for our sample.

In general, our results show that the elasticity of technical change with respect to firm size increases with size. The elasticity attains the value of unity for firms slightly smaller than the median firm size in our sample. While the indirect effect, discussed above, falls with increases in size, the direct effect rises more than enough to offset this decline.

\section{The Comanor Study}

Of course, the major difficulty in studies of technical change is to find a proper way of measuring it. Technical change in the pharmaceutical industry primarily takes the form of new product invention and innovation. Comanor elected to measure technical change by the variables $Y_{1}$ and $Y_{2}$, where

$Y_{1}=$ total sales during the first two calendar years following introduction of all new chemical entities introduced by the firm during the period 1955-1960.

$Y_{2}=$ total sales during the first two calendar years following introduction of all new chemical entities, duplicate products, combination products, and new dosage forms introduced by the firm during the period 1955-1960.

Paul de Haen, a consultant, has maintained a complete classification system for all new products introduced in the United States pharmaceutical industry. New chemical entities are new drugs not previously marketed in the United States, duplicate products are drugs offered as a single ingredient, but also sold by other firms, and combination products are preparations consisting of more than one active ingredient.

de Haen's system is primarily concerned with the technical characteristics of new products. For example, it is probably reasonable to view new chemical entities as requiring a higher degree of inventive skill than that required for duplicate products, combination products, or new dosage forms. In order to assess the economic impact of the products, Comanor weighted each new product on the basis of its sales during the first two calendar years following introduction.

The "importance" of a new drug is determined by its contribution to social welfare. Ideally this contribution should be measured as the net (of effects on substitutes) addition to consumers' surplus plus producers' profits caused by the introduction of the new drug. Sales of the new drugs during the two years following introduction serves as a proxy for this measure of importance. ${ }^{3}$

Comanor estimated the following regression for a sample of 57 pharmaceutical firms

$$
\begin{aligned}
Y / S & =0.422-\quad 4.671 R / S+\underset{(5.1)}{0.547} R^{2} / S \\
& +\underset{(-3.6)}{0.00003 S-\quad 0.00000012 R \cdot S} \\
& \begin{array}{l}
(3.7) \quad 0.13 D ; \quad(-4.0) \\
(-3.2) \quad n=57, \quad R^{2}=0.40
\end{array}
\end{aligned}
$$

(note: $t$-values are numbers in parentheses)

where $Y=$ sum of first two years' sales of all new chemical entities introduced by firm in 1955-1960

$R=$ number of professional $\mathrm{R}$ and $\mathrm{D}$ personnel of firm

$S=$ sales of ethical drugs of firm

$D=$ diversification in ethical drugs

The variable $R \cdot S$, an interaction variable, was introduced in addition to $S$ to try to pick up two separate effects of firm size. Comanor hypothesized that $R \cdot S$ would pick up the effect of increased problems of organization and administration while $S$ would pick up the effect of better distribution facilities and selling capabilities that tend to be associated with larger firm size.

He deflated $Y, R$, and $R^{2}$ by $\mathrm{S}$ in order to increase the likelihood that the assumption of homoscedasticity was satisfied. Multiplying

\footnotetext{
3 While Comanor apparently used the first two calendar years of sales, we have used the sales in the twenty-four months immediately following introduction.
} 
both sides of the equation by $S$, Comanor then computed the marginal product of $Y$ with respect to $R$, or

$$
\partial Y / \partial R=-4.671-0.00000012 S^{2}+1.09 R .
$$

From this result, Comanor concluded that "the marginal productivity of professional research personnel is inversely related to size of firm" (1965, p. 187).

For comparative purposes, we present below a re-estimation of the Comanor equation using data for the 1965-1970 period. (A complete description of our sample and variables is provided later.)

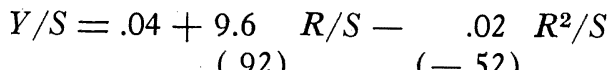

$$
\begin{aligned}
& \begin{array}{cc}
(.92) & (-.52) \\
+ & .000002 S-\quad .0000000009 R \cdot S
\end{array} \\
& \text { (2.9) (-.94) } \\
& +.02 D \\
& \text { (.09) } \\
& n=50, \quad R^{2}=.20
\end{aligned}
$$

Generally, our variables are defined similarly to those of Comanor, with one exception. His index of diversification was the product of the number of markets serviced by the firm and the proportion of sales outside the firm's primary market. Our measure is a Herfindahl-type index.

Clearly, our results are statistically much worse than those of Comanor. We can explain only about half as much of the variation in $Y$ and our $t$-values, given in parentheses, are lower and indicate that the coefficient of $S$ is the only statistically significant one. ${ }^{4}$

The influence of firm size on technical change is of central importance in the study. There are in Comanor's specification both positive and negative effects of size on technical change. That is, the coefficient of $S$ is positive and is interpreted as evidence of superior selling capabilities of large firms. The coefficient of $R \cdot S$ is negative and is interpreted as evidence of diseconomies of large scale. While there is no way to disprove this interpretation, a model specifically designed to separate the effect of

\footnotetext{
${ }^{4}$ In preliminary work we ran regressions of $Y$ on $R$ and $S$ for both quadratic and logarithmic specifications. The coefficients of the $S$ variable were generally positive and significant, but other coefficients were usually insignificant. The explained variation was low in all cases, $20 \%$ or less. Hence, we concluded that the single equation approach was inappropriate and that some device for disaggregating the innovative process was necessary.
}

size as exerted through the alternate channels of organizational and selling capabilities would be preferred.

We have developed a model that appears to meet this requirement. Essentially, we break the measure of technical change into two components and use a two-equation approach. The first equation relates size to the number of new products developed; hence, it permits us to omit the use of size as a proxy for selling capability effects. The second equation relates the average sales per new product to size and thereby permits us to study the selling capability effect separately from $R$ and $D$ considerations.

\section{The Two-equation Model}

The model can be written simply as the identity

$$
Y=(C E)(Y / C E) \text {. }
$$

We hypothesize that the two factors on the right-hand side of equation (3) represent the output of two distinct activities of the firm, viz, $C E$ measures the firm's $R$ and $D$ activity and $Y / C E$ measures the firm's marketing activity. After describing the relationships between $C E$ and firm size and between $Y / C E$ and firm size, it is possible to establish the total effect of firm size on technical change, or $Y$. For example, if the elasticity of $C E$ with respect to size is $x$ and the elasticity of $Y / C E$ with respect to size is $y$, then the elasticity of $Y$ with respect to firm size is simply $(x+y)$.

Clearly, the dichotomy may be somewhat artificial. The firm's decisions as to the particular research projects that it embarks upon undoubtedly are influenced to some extent by marketing considerations. ${ }^{5}$ However, the advantages of the dichotomy in terms of simplicity and directness of interpretation would appear to justify the assumption that the activities can be considered separately. For example, we can disentangle the selling capability effect of firm size from the $R$ and $D$ effect of firm size, the problem that led to difficulties of interpretation in the Comanor work.

\footnotetext{
5 On the other hand, discussions with some pharmaceutical executives have led us to believe that decisions regarding research projects to be undertaken often turn upon the skills and knowledge of existing researchers rather than upon a thorough-going analysis of market potentials.
} 
The Sample

In selecting the sample of firms, we were constrained by data limitations. Firms were included in the sample only if data could be obtained for the number of their professional $\mathrm{R}$ and $\mathrm{D}$ personnel. Generally, this was the most binding constraint since data for other variables were more readily available.

The final sample contains 50 firms. As Comanor noted in his work, the sample is essentially nonrandom and conclusions are applicable only to it and not to the total industry. However, the sample does account for approximately $88 \%$ of total industry sales and therefore should be representative of the total industry.

The size distribution of the 50 firms has a median of $\$ 31.9$ million of ethical drug sales. The mean of the distribution is $\$ 60.6$ million and the range is from a low of $\$ 0.7$ million to a high of $\$ 246.6$ million. The number of $R$ and $D$ professionals ranges from 2 to 1105 . The median staff is 93 and the mean is 190 .

\section{The Variables}

For the convenience of the reader, we present below a list of all variables to be used in the paper.

$Y=$ total sales during the first twenty-four months following introduction of all new chemical entities introduced by the firm ${ }^{6}$ from 1965 to 1970

$C E=$ the number of all new chemical entities ${ }^{7}$ introduced by the firm from 1965 to 1970

$D=$ a Herfindahl-type index of diversification ${ }^{8}$ in ethical drugs for the firm, in 1968

\footnotetext{
6 See footnotes 7 and 12 for definitions of new chemical entities and total sales.

7 According to de Haen, 102 new chemical entities were introduced in the United States during the 1965-1970 period. This compares with 276 new chemical entities introduced during the 1955-1960 period. An important reason for this large decline is that the regulations for acceptance of new drugs were tightened in 1962. Prior to 1962 , the basic requirement was that new drugs had to be shown to be safe; however, the new regulation requires proof that new drugs have the effects claimed for them. See Baily (1972) for an analysis of the effect of this change in regulations. Firms in our sample account for all but 8 of these 102 new chemical entities. For various reasons, we excluded 33 additional $C E$. Twenty-two were developed by foreign laboratories and were only first marketed in the United States by the firms in our sample. Others were excluded for such reasons as finding that the actual introduction occurred in 1964, etc. Much of de Haen's data can be found in various issues of American Professional Pharmacist and Drug Cosmetic Industry.

8 This index was constructed using data from a mar-
}

$M=$ industry sales in the therapeutic class ${ }^{9}$ into which the new product was introduced in the year of introduction, in thousands of dollars

$P=$ promotional expenditures ${ }^{10}$ made by the firm, averaged for 1968 and 1969, in thousands of dollars

$R=$ the number of professional $R$ and $D$ personnel ${ }^{11}$ of the firm in 1970

$S=$ the sales of ethical drugs ${ }^{12}$ in the United States by the firm to hospitals and drug

keting research firm, Lea Associates. In a special report for the year 1968, an analysis of pharmaceutical manufacturers was prepared in which each firm's total prescription sales were distributed among twenty-two diagnosis classes (e.g., infective and parasitic diseases, neoplasms, allergic disorders, etc.). Taking the fraction of prescription sales in the $i^{\text {th }}$ class as $s_{i}$, the diversification index equals (1$\left.\Sigma s_{i}^{2}\right)$.

9 If a single firm introduced more than one product, $M$ was calculated as the mean value of the individual products' $M$. Classification as to therapeutic class followed Davee, Koehnlein and Keating.

10 Data on promotional expenditure per firm were obtained from Lea Associates' National Journal Audit, National Mail Audit and National Retailing Audit. Dollar expenditure figures were given for mail and journal promotion. Promotional visits by company representatives to physicians (given in terms of minutes) were valued at $\$ 4.00$ per minute, as suggested by Lea Associates.

11 Data on the numbers of $R$ and $D$ personnel were obtained in the 13th edition of National Academy of Sciences - National Research Council, Industrial Research Laboratories of the United States for 1970. While data on research and development expenditures can be obtained from annual reports for about fourteen or so firms, we elected to follow Comanor's use of numbers of $R$ and $D$ personnel in order to increase the sample size. There are also some advantages, e.g., it is frequently possible to determine a firm's allocation of total $\mathbf{R}$ and $\mathbf{D}$ by function (pharmaceuticals, industrial chemicals, etc.) whereas this is not possible using annual report data. We would have preferred to use the numbers of $R$ and $D$ professionals for a year earlier than 1970, but our sample would have been reduced by fifteen firms if we had used the 1965 edition of Industrial Research Laboratories.

Finally, we did use annual report data for $\mathbf{R}$ and $D$ expenditures in several regressions and obtained similar results to those given later in the paper. For example, we obtained the following version of equation (5)

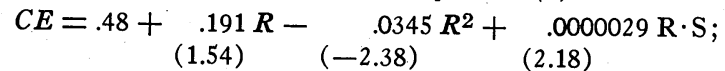

$$
\begin{aligned}
& n=14, R^{2}=.37
\end{aligned}
$$

12 Data on sales of ethical drugs were obtained from a marketing research firm, Davee, Koehnlein, and Keating. These data are based on a projection from a 1000 drug store sample to the population of all United States drug stores. The hospital data is based on a sample of about $10 \%$ of total hospital beds. A shortcoming of our sales data is that only about $80 \%$ of total United States sales is included. Government sales, for example, are excluded. Hence, we must assume that our results would not be greatly affected if total sales were used. We have made no attempt to adjust the figures for price level changes. 
stores, averaged for 1965 and 1970, in thousands of dollars

\section{The $R$ and $D$ Activity}

The general specification is

$$
C E=C E(R, S, D) \text {. }
$$

There are several hypotheses that are of interest in considering the factors that influence the number of new chemical entities developed. A major one relates to the question of whether a larger $\mathrm{R}$ and $\mathrm{D}$ staff is more efficient than a smaller one. One reason for expecting larger staffs to be more efficient is, of course, the specialization of personnel. To investigate this relationship we included both $R$ and $R^{2}$ as independent variables, thereby allowing for the possibility of a nonlinear relationship.

Another important question is whether an $\mathrm{R}$ and $\mathrm{D}$ staff of a given size operates more efficiently in a larger firm. One argument is that bigger firms are usually engaged in more activities, so knowledge produced is more likely to be usable. On the other hand, there may be organizational inefficiencies that tend to offset this effect. In order to examine this question we included an interaction variable equal to the product of $R$ and $S$, or $R \cdot S$.

A specification well-suited for taking nonlinearities and interactions into account is the logarithmic specification. Unfortunately, the dependent variable in our sample takes the value of zero for 21 of the 50 observations. Since the logarithm of zero does not exist, we did not estimate the logarithmic specification. ${ }^{13}$

Equation (5) indicates that there are diminishing returns to $\mathrm{R}$ and $\mathrm{D}$ for a given firm size. ${ }^{14}$ The coefficient of the interaction variable,

\footnotetext{
13 As Scherer (1965) has shown, it is dangerous to try to avoid this problem by assigning an arbitrarily small number for zero. The fact that there is a concentration of zeros at the lower limit of the range of the dependent variable also poses a statistical problem. Tobin (1958) has developed a procedure for handling this problem which we shall make use of in a later section.

Our quadratic specification is virtually the same as the one used by Mansfield (1964) in a study of the chemical, petroleum, and steel industries. If the intercept is suppressed, the specification is identical to Mansfield's and can be interpreted as postulating that the expected number of CE's per professional $R$ and $D$ worker is a linear function of $R$ and $S$. Suppressing the intercept in our study produced no difference in the signs and significance of the coefficients, although the $R^{2}$ fell by two percentage points.

14 We tried also a second measure of research personnel.
}

$R \cdot S$, is positive and statistically significant. Thus, increasing firm size has a positive effect on $R$ and $D$ output.

$$
\begin{aligned}
C E & =.35+\underset{(1.75)}{.0043 R}-\underset{(-4.27)}{.000019 R^{2}} \\
& +\underset{(3.40) \quad .000000076 R \cdot S}{\quad n=50, \quad R^{2}=.38 .}
\end{aligned}
$$

Equation (5) does not contain the diversification variable, $D$. Its coefficient was found to be insignificant and $D$ was dropped from the study. ${ }^{15}$

For the present, we defer further analysis of equation (5).

\section{The Marketing Activity}

Average sales per new product, $Y / C E$, is attributed in our model to selling capability (measured by the amount of expenditures on promotion, $P$ ) and to the firm size, $S$. An additional influence, the current sales volume of the therapeutic class into which the new product is introduced, $M$, is also considered. The general specification is

$$
Y / C E=Y / C E(S, M, P) \text {. }
$$

The logarithmic specification is appropriate here and no problem is encountered because of zero-valued dependent variables. Although the sample is reduced to 29 observations, this is as it should be. No meaning can be attached to a measure of marketing effectiveness for firms having no new products to sell.

Rather than only the number of professional $\mathbf{R}$ and $\mathrm{D}$ personnel, we calculated a measure RT equal to the total of professionals, technicians, and auxiliary personnel. When RT was substituted for $\mathbf{R}$, the results were generally inferior. That is, while the algebraic signs were the same, the $t$-values and the coefficient of determination were lower. For example, the RT version of equation (5) had an $R^{2}$ of 0.30 (compared to 0.38 for the $R$ version) and the $t$-value for the coefficient of $\mathrm{R} \cdot \mathrm{S}$ was only 1.13 (compared to 3.40 ). The other variables were statistically significant. We might also note that the simple correlation coefficient between $R$ and $R T$ is 0.93 .

15 A concern for multicollinearity led us to examine the partial correlation coefficients between all of the independent variables. In making such an examination we found that the highest coefficient was 0.88 between the square of $R$ and $R \cdot S$. The next highest partial correlation coefficient was only 0.38 , between $R$ and $R \cdot S$. Of course, the definitions of the variables insure some induced correlations. Given that the coefficients of these variables were, in most cases, highly significant according to the usual $t$-test, and that alternate formulations of the variables could not be found to test the desired hypotheses, we have chosen to accept the results in equation (5) as being meaningful. 


$$
\begin{aligned}
\log (Y / C E) & =-7.11+\underset{(4.57)}{.744 \log S} \\
& +\quad .579 \log M . \\
& \quad n=29, \quad R^{2}=.56
\end{aligned}
$$

The simple correlation coefficient between $P$ and $S$ is 0.93 , thereby causing a collinearity problem. Since our primary interest is the effect of size on the dependent variable, we elected to drop $P$ and to interpret $S$ as measuring both $P$ and $S$.

The coefficients of $S$ and $M$ are both positive, as expected, and highly significant. We might note that spurious correlation between $Y$ and $M$ is probably unimportant because new product sales make up less than $5 \%$ of $M$ on the average. Given the good statistical results in equation (7), we shall use it in further analysis.

\section{Analysis of Results}

Based upon the empirical results discussed earlier, we shall take equation (5) to be the best description of the $R$ and $D$ activity. Thus, the marginal product of $\mathrm{R}$ can be computed as $\partial C E / \partial R=.0043-.000038 R$

$$
+.000000076 S \text {. }
$$

The marginal product of research personnel increases with size and decreases with $\mathrm{R}$. Thus, our evidence suggests that a given $R$ and $D$ staff is more efficient in developing new chemical entities if it is located in a larger firm.

We should note here a possible contributing factor to the finding that size has a positive effect on the marginal product. Our measure of research input is the number of personnel and not the total input of resources into the firm's research activity. A report of the Pharmaceutical Manufacturers Association (1972) indicates that larger firms have higher total $R$ and $D$ expenditures per $R$ and $D$ employee than smaller firms. Hence, to some unknown extent, the variable $S$ in our regressions may be serving as a proxy for these higher expenditures.

Equation (8) shows that the marginal product is greater in larger firms, for a given $R$ and $D$ staff. However, larger firms generally support larger $\mathrm{R}$ and $\mathrm{D}$ activities. Regressing the logarithm of $R$ on the logarithm of $S$, we obtain $^{16}$

16 The investigation of the relationship between size and

$$
\begin{aligned}
\log R=-4.91+ & .906 \log S . \\
& (13.8) \\
& n=50, \quad R^{2}=.80
\end{aligned}
$$

Hence, two factors are at work as we increase firm size: (1) larger size shifts the marginal product schedule up and to the right, and (2) larger size leads to an increase in $R$, as indicated in equation (9). Since the marginal product falls with an increase in $R$, it is clear that the net effect of an increase in size depends upon which factor is larger.

A useful way of investigating this question is to compute the elasticity of new chemical entities with respect to firm size for alternate sizes. This elasticity is equal to

$$
\begin{aligned}
e(C E, S) & =\left(\frac{\partial C E}{\partial R} \cdot \frac{R}{C E}\right)\left(\frac{d R}{d S} \cdot \frac{S}{R}\right) \\
& +\frac{\partial C E}{\partial S} \cdot \frac{S}{C E}
\end{aligned}
$$

The first term on the right-hand side measures the "indirect" percentage increase in $C E$ due to a one per cent increase in size. It is termed "indirect" because it is due to an increase in $\mathrm{R}$ and $\mathrm{D}$ staff induced by the increase in size. That is, if we take account of equation (9), we observe that a one per cent increase in size produces a 0.906 per cent increase in $R$ and $\mathrm{D}$ staff. ${ }^{17}$ This increase in staff then produces the indirect effect of a change in firm size on the number of new chemical entities developed. The second term on the right-hand side of equation (10) represents the "direct" effect of an increase in size on $C E$ 's developed.

$\mathbf{R}$ and $\mathbf{D}$ input has been pursued by several authors (see references in footnote 1 ). In this study various functional forms of the $R, S$ association were explored. A quadratic specification indicated that $R$ increases with $S$ at an increasing rate, although the coefficient of $S$ was not significant. The log-log specification presented in equation (9) proved statistically superior, and was chosen for deriving the elasticity estimates. We might add that the elasticity of $R$ with respect to $S$ indicated in equation (9) is quite consistent with the findings of others.

17 The use of equation (9) implicitly raises the question of the proper estimation technique for the basic CE equation. That is, one could consider the CE equation and equation (9) to be part of a simultaneous system of equations, thereby calling for the use of a simultaneous equation estimation technique. We have not elected to follow such an approach here because our interest is primarily confined to the "production function-type" relations and the specification of a complete simultaneous equation model is beyond the scope of this study. For an examination (and rejection) of the possibility that technical change influences $R$ and $D$ staff rather than the reverse, see Comanor (1965). 
Table 1. - Elasticity of $C E$ with Respect to $S$

\begin{tabular}{ccccc}
\hline \hline (1) & $\begin{array}{c}(2) \\
\text { (3) }\end{array}$ & $\begin{array}{c}\text { (4) } \\
\text { e(CE,S) }\end{array}$ & $\left(\frac{\partial C E}{\partial R} \cdot \frac{R}{C E}\right)\left(\frac{d R}{d S} \cdot \frac{S}{R}\right)\left(\frac{\partial C E}{\partial S} \cdot \frac{S}{C E}\right)$ & $\begin{array}{c}\text { (5) } \\
\text { (millions of } \\
\text { dollars) }\end{array}$ \\
\hline 0.16 & 0.16 & 0.91 & 0.01 & 5 \\
0.27 & 0.24 & 0.91 & 0.05 & 10 \\
0.58 & 0.37 & 0.91 & 0.25 & 30 \\
0.97 & 0.34 & 0.91 & 0.66 & 70 \\
1.15 & 0.29 & 0.91 & 0.89 & 100 \\
1.35 & 0.21 & 0.91 & 1.16 & 150 \\
1.49 & 0.16 & 0.91 & 1.34 & 200 \\
1.58 & 0.13 & 0.91 & 1.46 & 250 \\
\hline
\end{tabular}

Table 1 represents the computed values of $\mathrm{e}(\mathrm{CE}, \mathrm{S})$ for alternate firm sizes.

The first column of the table shows that the total elasticity of $C E$ increases with size throughout the range of sizes. Since the largest firm in the sample had an $S$ of $\$ 247$ million, we would be unwilling to project elasticities for any sizes greater than $\$ 250$ million. An elasticity of unity is attained at a size slightly greater than $\$ 70$ million. (Recall the mean size in the sample is $\$ 61$ million.) Larger firms seem to have an advantage over smaller firms in the development of new chemical entities.

It is interesting to examine the pattern of the indirect and direct components of the total elasticity. The second column of table 1 shows that the indirect effect is not the source of the advantage of larger firms. In fact, the elasticity of $C E$ with respect to $\mathrm{R}$ and $\mathrm{D}$ staff declines rapidly after a size of $\$ 30$ million is passed. Furthermore, the elasticity is always less than unity, indicating that doubling $\mathrm{R}$ yields a less than doubling of $C E$ for all firm sizes. Column (4) shows that it is the direct effect of size on $C E$, holding $\mathrm{R}$ and $\mathrm{D}$ staff fixed, that gives the large firms the overall advantage.

Thus, while there are diminishing returns to increases in $\mathbf{R}$ and $\mathbf{D}$ staff, there are increasing returns to locating fixed $R$ and $D$ staffs in larger firms. And, the increasing returns are, on balance, more important in determining the total effect of firm size on the development of new chemical entities. ${ }^{18}$

\footnotetext{
18 As mentioned in the introduction, we re-estimated the CE equation for 1955-1960 data. Equation (5a) below is comparable to equation (5) in the text, but was estimated for the pre-1962 period.

$$
\begin{aligned}
C E=.60+\underset{(2.89)}{.026 R}-\underset{(-2.09)}{.000022 R^{2}}+\underset{(1.93)}{.000000138 R \cdot S} \\
n=42, \quad R^{2}=.79
\end{aligned}
$$

Before turning to the elasticity of $Y$ with respect to size analysis, we need to consider an econometric problem. Tobin (1958) has developed a maximum likelihood estimation technique to handle cases where there is a concentration of observations on the dependent variable at a limit. As discussed earlier, the dependent variable $C E$ is limited on the low side by zero, and 21 of the 50 firms in the sample have $C E$ values of zero.

The assumptions of the multiple regression model are not realized under such circumstances. "According to that model, it should be possible to have values of the explanatory variables for which the expected value of the dependent variable is its limiting value; and from this expected value, as from other expected values, it should be possible to have negative as well as positive deviations". (Tobin, 1958, p. 25).

Following Tobin (1958, p. 26), we computed the expected values ${ }^{19}$ of $C E$ for alternate values of $R$ and $S$. A comparison of the limited dependent variable (LIM) estimates with the OLS estimates reveals that the OLS estimates tend to understate the effectiveness of relatively large $\mathrm{R}$ and $\mathrm{D}$ staffs, other things held constant.

We present in table 2 a comparison of the

The 42 firms ranged in size from a low of $\$ .3$ million in sales to a high of $\$ 141.2$ million, with a median of $\$ 9.1$ million. A comparison of the elasticities of CE with respect to size for the two periods is given below (the elasticities given in parentheses were computed from versions of equations (5) and (5a) in which the intercepts were suppressed)

$\begin{array}{ccc}\mathrm{S} & & \\ \text { (millions of } \$) & 1955-1960 & 1965-1970 \\ 10 & 0.54(0.91) & 0.27(0.94) \\ 30 & 0.79(0.93) & 0.58(1.02) \\ 70 & 0.99(0.97) & 0.97(1.16) \\ 100 & 1.09(1.00) & 1.15(1.25) \\ 150 & 1.20(1.05) & 1.35(1.37)\end{array}$

An interesting implication is that the 1962 Amendments may have resulted in a "tilting" of the schedule relating elasticity to size such that the relative advantage of larger firms has become greater.

Finally, we might note that we pooled the data and introduced a dummy variable equal to unity for the 1965-1970 data and zero otherwise. The coefficient of the dummy was negative and highly significant, indicating a downward shift in the function over time. This is consistent with the findings of Baily (1972) and Peltzman (1973) regarding the impact of the 1962 Amendments.

$19 \mathrm{We}$ are grateful to Professor Alvin Klevorick of Yale University for sending us a computer routine designed to produce the maximum likelihood estimates and expected values for Tobin's model. 
TABLE 2.-Comparison of OLS and LIM Elasticity of CE Estimates

\begin{tabular}{|c|c|c|}
\hline OLS: $e(C E, S)$ & LIM $: e(C E, S)$ & $\begin{array}{c}\text { (3) } \\
S \\
\text { (in millions } \\
\text { of dollars) }\end{array}$ \\
\hline 0.16 & 0.10 & 5 \\
\hline 0.27 & 0.19 & 10 \\
\hline 0.58 & 0.53 & 30 \\
\hline 0.97 & 1.13 & 70 \\
\hline 1.15 & 1.43 & 100 \\
\hline 1.35 & 1.63 & 150 \\
\hline 1.49 & 1.65 & 200 \\
\hline 1.58 & 1.66 & 250 \\
\hline
\end{tabular}

OLS and LIM estimates of the elasticity of $C E$ with respect to firm size, or $e(C E, S)$.

Thus, the LIM estimates of $e(C E, S)$ are lower for smaller sizes and higher for larger sizes than the OLS estimates. More importantly, the general tendency of larger sizes to have higher elasticities is unaffected.

\section{Size and Technical Change}

We have argued previously that society should be more interested in $C E$ weighted by sales (the variable $Y$ ) than in $C E$ only. Hence, we now examine the elasticity of $Y$ with respect to $S$. This elasticity is defined as

$$
\begin{aligned}
e(Y, S) & =\left(\frac{\partial Y}{\partial R} \cdot \frac{R}{Y}\right)\left(\frac{d R}{d S} \cdot \frac{S}{R}\right) \\
& +\frac{\partial Y}{\partial S} \cdot \frac{S}{Y} .
\end{aligned}
$$

Because of the form of the $Y / C E$ equation, it is possible to relate $e(Y, S)$ to $e(C E, S)$ in a quite simple manner. Since,

$$
e(Y, S)=e(C E, S)+e(Y / C E, S)
$$

and $e(Y / C E, S)=0.744$, we can derive a table of elasticities of $Y$ with respect to $S$ by simply adding the constant 0.744 to each entry in table 2. We shall not do so here; rather, we simply note that the advantages of size become even more pronounced when we weight $C E$ by some measure of economic importance.

\section{Concluding Remarks}

As Fisher and Temin have argued, the important issue for public policy formulation is how the output of $R$ and $D$ varies with size of firm. In this paper, we have tried to examine this issue for an industry in which unusually good data are available. Our results indicate that larger pharmaceutical manufacturers appear to have decided advantages over smaller ones in accomplishing technical change. These results do not appear to be unreasonable when it is realized that the very largest firm in the industry is still relatively small when compared with American manufacturing in general. Thus, the main theoretical argument for expecting decreasing returns in producing technical change in large firms - organizational inefficiencies may not yet be a problem in ethical drugs.

\section{REFERENCES}

Baily, M. N., "Research and Development Costs and Returns: The U.S. Pharmaceutical Industry," Journal of Political Economy (Jan./Feb. 1972).

Comanor, W. S., "Research and Technical Change in the Pharmaceutical Industry," this REviEw (May 1965).

- "Market Structure, Product Differentiation, and Industrial Research," Quarterly Journal of Economics (Nov.. 1967).

-, "Research and Competitive Product Differentiation in the Pharmaceutical Industry in the United States," Economica (Nov. 1964).

-, "The Drug Industry and Medical Research," Journal of Business (Jan. 1966).

Cooper, M. H., Prices and Profits in the Pharmaceutical Industry (London: Pergamon Press, 1966).

Farrar, D. E., and R. R. Glauber, "Multicollinearity in Regression Analysis: The Problem Revisited," this REVIEW (Feb. 1967).

Kane, E. J., Economic Statistics and Econometrics (New York: Harper and Row, 1968).

Fisher, F. M., and P. Temin, "Returns-to-Scale in Research and Development: What does the Schumpeterian Hypothesis Imply"? Journal of Political Economy (Jan./Feb. 1973).

Mansfield, E., "Industrial Research and Development Expenditure: Determinants, Prospects, and $\mathrm{Re}$ lation of Size of Firm and Inventive Output," Journal of Political Economy (Aug. 1964).

Peltzman, S., "An Evaluation of Consumer Protection Legislation: The 1962 Drug Amendments," Journal of Political Economy (Sept./Oct. 1973).

Pharmaceutical Manufacturers Association, Annual Survey Report 1970-1971, Washington, D.C. (Feb. 1972).

Scherer, F. M., "Size of Firm, Oligopoly, and Research, A Comment," Canadian Journal of Economics and Political Science (May 1965).

Scherer, F. M., "Firm Size, Market Structure, Opportunity, and the Output of Patented Inventions," American Economic Review (Dec. 1965).

Schifrin, L. G., "The Ethical Drug Industry: The Case for Compulsory Patent Licensing," Antitrust Bulletin (Fall, 1967).

Schmookler, J., "Bigness, Fewness, and Research," Journal of Political Economy (Dec. 1959). 
Steele, H., "Monopoly and Competition in the Ethical Drugs Market," Journal of Law and Economics (Oct. 1962).

-, "Patent Restrictions and Price Competition in the Ethical Drugs Industry," Journal of Industrial Economics (July 1964).

Tobin, J., "Estimation of Relationships for Limited Dependent Variables," Econometrica (Jan. 1958).

Vernon, J. M., "Concentration, Promotion, and Market
Share Stability in the Pharmaceutical Industry," Journal of Industrial Economics (July 1971).

$\longrightarrow$ - Market Structure and Industrial Performance: $A$ Review of Statistical Findings (Boston: Allyn and Bacon, 1972).

Villard, H., "Competition, Oligopoly and Research," Journal of Political Economy (Dec. 1958).

Worley, J. S., "Industrial Research and the New Competition," Journal of Political Economy (Apr. 1961). 